\title{
Gestão da análise de resíduos presentes na água gerada da lavagem dos gases oriundos do processo de redução da cassiterita a estanho em alto-fornos, em uma empresa minero-metalurgia do município de Ariquemes, Rondônia.
}

\author{
Karina Bianchini ${ }^{1}$, Filomena Maria Minetto Brondani ${ }^{2}$, Naila Fernanda Sbsczk Pereira Meneguet- \\ ti $^{3}$, Dionatas Ulises de Oliveira Meneguetti ${ }^{4}$, Renato André Zan ${ }^{5}$ \\ ' Graduada em Química pela Faculdade de Educação e Meio Ambiente (FAEMA), Ariquemes, RO. Brasil. \\ ${ }_{2}^{2}$ Mestre em Biologia Experimental, Coordenadora do Curso de Graduação em Química da (FAEMA), Ariquemes, RO. Brasil. \\ ${ }^{3}$ Mestrando em Administração (PPGMAD), da Fundação Universidade Federal de Rondônia (UNIR), Porto Velho, RO. Brasil. \\ ${ }^{4}$ Doutorando em Biologia Experimental (PPGBIOEXP), da (UNIR), Porto Velho, RO. Brasil. \\ ${ }^{5}$ Mestre em Química, Docente do Instituto Federal de Educação Ciências e Tecnologia de Rondônia (IFRO), Ji-paraná, RO. Brasil.
}

\begin{abstract}
Resumo
A importância na preservação do meio ambiente tem por definição garantir uma melhor qualidade de vida para o ambiente que nos cerca e das futuras gerações, importância essa que leva a estudos que minimizem o impacto ambiental causado por indústrias que utilizam água em seu processo produtivo. O presente estudo envolveu uma empresa de fundição de minério de cassiterita Estanho de Rondônia do município de Ariquemes-RO, tendo seu objetivo centrado na avaliação da qualidade da água residual gerada do processo da lavagem de gases oriundos dos fornos elétricos, estes destinados à redução do minério de cassiterita. As amostras foram coletadas em duas etapas, sendo na segunda etapa adicionado o reagente hidróxido de sódio para um processo neutralização e precipitação e processo de agitação por ar comprimido. $\mathrm{O}$ laboratório responsável pela análise foi a Bioagri Ambiental com parâmetros do Conselho Nacional do Meio Ambiente (CONAMA) 357/05 art. 34. Os resultados da primeira etapa apresentaram quatro parâmetros fora do Conama 357/05 a exemplo fluoreto $710 \mathrm{mg} / \mathrm{L}$, estanho total 6,4 mg/L, ferro dissolvido 34,8 mg/L, e pH 2,74 mg/L. Observa-se que na segunda etapa com o uso do reagente hidróxido de sódio o resultado analítico apresentou somente um parâmetro fora da resolução Conama, o fluoreto $810 \mathrm{mg} / \mathrm{L}$, com valor máximo permitido de 10,0 mg/L. Embora havendo uma redução significativa dos contaminantes conclui-se que somente o hidróxido de sódio não satisfaz o esperado processo de tratamento, exigindo assim, um estudo mais aprofundado no tratamento da água residual para que a mesma possa ser descartada ou reutilizada no processo de produção da empresa.
\end{abstract}

Palavras-chave: Processamento de cassiterita, Meio Ambiente, Água Residual.

\begin{abstract}
The importance of the environment is by definition to ensure a better quality of life for the environment around us and future generations, which leads to the important studies that minimize the environmental impact caused by industries that use water in its production process. This study about a foundry cassiterite (tin ore) from the city of Ariquemes Rondônia - RO, and focused on your objective assessment of the quality of wastewater generated from washing of the process gases from the electric furnaces for the reduction of these ore cassiterite. Samples were collected in two stages, the second step reagent added sodium hydroxide to a neutralization and precipitation process and stirring by compressed air. The laboratory responsible for analysis was Bioagro Ambiental parameters with CONAMA 357/05 art. 34. The results showed the first step out of the four parameters example fluoride National Council of Environment (CONAMA) 357/05 710 mg / $\mathrm{L}$, total tin $6.4 \mathrm{mg} / \mathrm{L}$, dissolved iron $34.8 \mathrm{mg} / \mathrm{L}, \mathrm{pH} 2.74 \mathrm{mg} / \mathrm{L}$. It is observed that in the second stage using sodium hydroxide reagent analytical results showed only one parameter out of CONAMA resolution, $810 \mathrm{mg}$ fluoride / L, with a maximum allowed of $10.0 \mathrm{mg} / \mathrm{L}$. Although there was a significant reduction in contaminants is concluded that only the sodium hydroxide does not only treatment process thus requiring. Further study in the treatment of wastewater so that it can be discarded and reused in the production process of the company. Keywords: Processing of cassiterite, Middle environment, Water residuary.
\end{abstract}




\section{INTRODUCCÃO}

O desenvolvimento industrial e o desordenado crescimento urbano foram acompanhados de um aumento da poluição ambiental fazendo com que, nas últimas décadas, a sociedade viesse a se preocupar de forma mais efetiva em avaliar e gerenciar os riscos para seres humanos e para o meio ambiente (MELAMED; PEDRO; LUIZ, 2002).

A contaminação por resíduos líquidos gerados por processos industriais vem chamando muito a atenção de ambientalistas por serem facilmente liberados ou transportados em ambientes aquáticos ou terrestres (TOREM; CUNHA; CASQUEIRA, 2005).

A presença de poluentes já foi identificada em regiões remotas do planeta como na Antártica onde se observou partículas contendo metais pesados. A maioria dos metais que ocorrem naturalmente na crosta terrestre não causa danos ao meio ambiente e/ou ao homem, no entanto, quando concentrados por processos antropogênicos ou naturais esses resíduos podem causar danos a fauna, à flora e aos seres humanos (PEREIRA, 2002).

Dentre as fontes de poluição antropogênicas se destacam os processos industriais, o uso de fungicidas e pesticidas, os rejeitos industriais e a queima de combustíveis fósseis. Diversos setores da indústria, dentre eles as mineradoras, podem gerar efluentes líquidos ou gasosos contribuindo para o aumento da poluição ambiental. Os processos de extração e beneficiamento dos minérios e estocagem de rejeitos produzem efluentes que podem ser dispersos para o meio ambiente e quando inalados e/ou ingeridos por trabalhadores e/ou pela população podem causar sérios danos à saúde (APOSTOLLI, 1992).

No Brasil, metais pesados como As, $\mathrm{Cu}, \mathrm{Zn}$, $\mathrm{Ni}, \mathrm{Pb}$, entre outros podem ocorrer associados a diversos minérios, tais como a tantalita, columbita, niobatotantalato, cassiterita, pirocloro, zirconita, ilmenita, rutilo, fosfatos, silicatos, carvão e monazita (CASTANHO; CRUZ, 1973).

Sabemos que a preocupação com o meio ambiente é tímida no Brasil, diferentes dos países desenvolvidos, a sociedade ainda não se conscientizou da importância de preservar os recursos naturais para a sua sobrevivência e que a forma de exploração ambiental vigente pode ameaçar a estabilidade dos seu sistemas de sustentação e no tocante a água não podemos esquecer que a mesma é, o principal constituinte de todos os organismos vivos (MORAES; JORDÃO, 2002).
Marcus (2011) comparando o homem à degradação ambiental diz que os interesses econômicos imediatos, continuam a estimular agressões ao ambiente, muitas vezes com a conivência dos órgãos públicos e dos meios de comunicação, sendo necessário aumentar os investimentos na preservação em acidentes ambientais e em tecnologias que favoreçam a minimização dos descartes de resíduos líquidos.

Formas de evitar problemas futuros de maior proporção é através de legislações rígidas e da consciência ecológica, pois o meio ambiente não se refere somente em áreas de preservação, e sim, tudo que nos cerca, água, ar, solo, flora, fauna, homem, e considerando que no município de Ariquemes, Rondônia atuam várias empresas mineradoras que processam cassiterita, esse estudo originou-se pelo interesse por essa atividade minero-metalurgia e pela problemática ambiental gerada pelos resíduos oriundos desse processo e com isso o presente estudo objetivou realizar uma gestão da análise de resíduos presentes na água gerada da lavagem dos gases oriundos do processo de redução da cassiterita a estanho em alto-fornos, de uma empresa minero-metalurgia, no município de Ariquemes, Rondônia.

\section{MATERIAIS E MÉTODOS}

\section{I Localidade de Estudo}

Este estudo foi realizado em uma empresa de redução de minério de cassiterita localizada no município de Ariquemes (Figura 1), cidade que se encontra localizada no estado de Rondônia, a $199 \mathrm{~km}$ da capital "Porto Velho", região norte do Brasil, sua área geográfica é de 4.426,56 km2 (2.002), com uma população de aproximadamente 90.353 habitantes (ZAN et al., 2012).

\subsection{Coleta e Processamento da Amostra}

As amostras foram coletas no tanque de depósito de água residual, oriunda da lavagem dos gases gerados no processo redução de cassiterita a estanho, posteriormente acondicionada em frascos padronizados e indicados pelo laboratório responsável pela análise. Após a coleta a mostra foi acondicionada em uma caixa térmica, refrigerada e enviada para análise.

As análises das amostras foram realizadas em triplicata, feitas por equipamentos como balança analítica para os parâmetros de óleos e graxas, cromatografia gasosa para o parâmetro para os Compostos Orgânicos Voláteis (VOC), analisador de cianeto para o parâmetro de cia- 


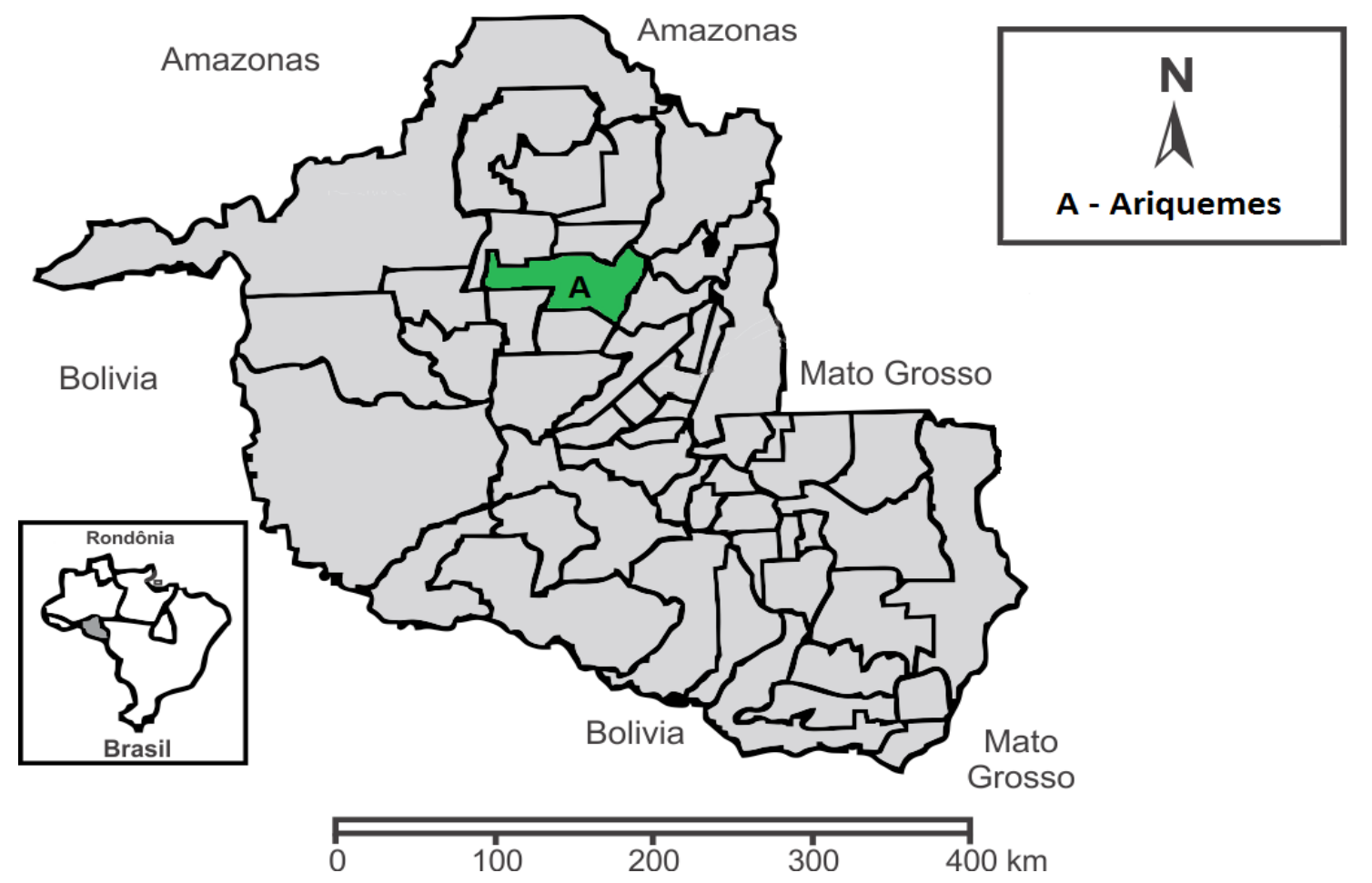

Figura 1 - Mapa de localização do Município de Ariquemes no Estado de Rondônia, Brasil

neto, potenciômetro íon seletivo para o parâmetro de nitrogênio amoniacal, espectrofotômetro de emissão por plasma para os parâmetros de metais, espectrofotômetro Ultra Violeta (UV) para os parâmetros de índices de fenóis; cromo hexavalente, cromatógrafo de íons para parâmetros de ânions e medidor para análise do Potencial Hidrogeniônico $(\mathrm{pH})$.

A retirada das amostras da segunda etapa foi após a neutralização com hidróxido de sódio, na qual foram adicionados $75 \mathrm{~kg}$ de hidróxido de sódio no tanque contendo 16.800 litros de água residual, concomitantemente com a homogeneização da solução através da injeção de ar comprimido, durante quatro horas de agitação e mais 24 horas de decantação. A adição do reagente na água residual foram a cada duas horas em quantidades de 25 $\mathrm{kg}$ por adição, com medição de $\mathrm{pH}$ constante até estabelecer um $\mathrm{pH}$ neutro. O processo de coleta foi o mesmo utilizado na primeira etapa.

\subsection{Parâmetros Utilizados na Análise da Água Residual}

Os parâmetros utilizados para a realização da análise e comparação de resultados foram os parâmetros da resolução CONAMA 357/2005 Art. 34. Visto que o Estado de Rondônia adota a Lei federal CONAMA como parâmetros para descarte de água residual ao meio ambiente (CONAMA, 2005).

\section{RESULTADOS E DISCUSSÃO}

De acordo com as análises da água residual resultante da lavagem de gases advindos do processo da redução da cassiterita a estanho e comparadas com Parâmetro utilizado CONAMA 357/05 art. 34 (CONAMA, 2005), observou-se que as concentrações de alguns contaminantes estão dentro dos limites máximos permitidos e outros acima destes, conforme (Tabela 1).

Os parâmetros $\mathrm{pH}$, estanho total, ferro dissolvido e fluoreto encontrado na tabela acima encontram-se acima dos valores máximos permitidos pelo CONAMA 357/05 de 25 de março de 2005, Artigo 34 em relação aos Padrões de lançamentos de efluentes - revisado pelo Conama 397. Lembrando que essa etapa teve como intuito verificar a qualidade da $\mathrm{H} 2 \mathrm{O}$ residual anterior a neutralização.

A segunda análise está sendo representada na (Tabela 2), na qual demonstra os resultados das análises da $\mathrm{H} 2 \mathrm{O}$ após a neutralização com hidróxido de sódio

Após adição do hidróxido de sódio verificou-se a maioria das concentrações dos contaminantes diminuíram, com exceção da concentração de fluoreto que aumentou.

$\mathrm{Na}$ (Tabela 03) e (Figura 2) podem ser observados uma comparação dos resultados apre- 
Tabela 01 - Resultados analíticos de água residual do processo de redução da cassiterita a estanho.

\begin{tabular}{|c|c|c|c|}
\hline Parâmetros & $\begin{array}{l}\mathrm{LQ} \\
(\mathrm{mg} / \mathrm{l})\end{array}$ & $\begin{array}{c}\text { Resultados } \\
\text { analíticos (mg/l) }\end{array}$ & $\begin{array}{c}\text { CONAMA } 357 \text { - Art. } \\
34 \text { VMP (mg/l) }\end{array}$ \\
\hline Cobre Dissolvido & 0,005 & 0,091 & 1,0 \\
\hline Ferro Dissolvido & 0,5 & 34,8 & 15,0 \\
\hline Manganês Dissolvido & 0,01 & 0,322 & 1,0 \\
\hline Fluoreto & 0,1 & 710 & 10,0 \\
\hline $\mathrm{pH}-\left[\mathrm{H}^{+}\right]$ & $0-14$ & 2,74 & $5-9$ \\
\hline Materiais sedimentáveis & 0,3 & 0,7 & 1,0 \\
\hline Óleos e Graxas Minerais & 1 & $<1$ & 20,0 \\
\hline Óleos e Graxas Vegetais e Animais & 1 & $<1$ & 50,0 \\
\hline Materiais flutuantes & -- & Ausentes & Ausentes \\
\hline Arsênio Total & 0,01 & $<0,01$ & 0,5 \\
\hline Bário Total & 0,01 & 0,250 & 5,0 \\
\hline Boro Total & 0,01 & 0,495 & 5,0 \\
\hline Cádmio Total & 0,001 & $<0,001$ & 0,2 \\
\hline Chumbo Total & 0,01 & $<0,01$ & 0,5 \\
\hline Cianeto & 0,1 & $<0,1$ & 1,0 \\
\hline Cianeto Livre & 0,02 & $<0,02$ & 0,2 \\
\hline Cromo Hexavalente & 0,01 & 0,02 & 0,1 \\
\hline Cromo Trivalente & 0,01 & $<0,01$ & 1,0 \\
\hline Cromo & 0,01 & 0,022 & --- \\
\hline Estanho Total & 0,5 & 6,4 & 4,0 \\
\hline Mercúrio Total & 0,00025 & $<0,00025$ & 0,01 \\
\hline Níquel Total & 0,01 & 0,029 & 2,0 \\
\hline Nitrogênio Amoniacal & 0,1 & 0,70 & 20,0 \\
\hline Prata Total & 0,005 & $<0,005$ & 0,1 \\
\hline Selênio Total & 0,008 & $<0,008$ & 0,30 \\
\hline Sulfeto & 1,0 & $<1$ & 1,0 \\
\hline Zinco Total & 0,01 & 0,790 & 5,0 \\
\hline Clorofórmio & 0,001 & $<0,001$ & 1,0 \\
\hline Dicloroeteno Total & 0,003 & $<0,003$ & 1,0 \\
\hline Índice de Fenóis & 0,02 & 0,15 & 0,5 \\
\hline Tetracloreto de Carbono & 0,001 & $<0,001$ & 1,0 \\
\hline Tricloroeteno & 0,001 & $<0,001$ & 1,0 \\
\hline
\end{tabular}

Fonte: Dados da análise laboratorial

sentados na (Tabela 01) e (Tabela 02) contendo a eficiência do reagente hidróxido de sódio na água residual.

Os parâmetros como $\mathrm{pH}$, do estanho e do ferro que anterior da neutralização ( $1^{\mathrm{a}}$ etapa) encontravam-se fora dos padrões, na segunda , após a neutralização suas concentrações alcançaram os parâmetros estabelecidos pelo CONAMA, 2005.

No tocante ao fluoreto não se encontra representado na figura acima, por apresentar valores que ultrapassaram a escala trabalhada. $\mathrm{Na}$ primeira análise o fluoreto

apresentou resultado de $710 \mathrm{mg} / 1$, com limite máximo permitido pelo CONAMA de 10,0 $\mathrm{mg} / 1$.e na segunda análise apresentou resultado de $810 \mathrm{mg} / 1$. Resultado esse que pode ter aumentado em consequência dos descartes de água residual no tanque de depósito no intervalo entre a primeira e segunda análise.

\section{I Sugestões Para Tratamento da Água Residual Gerada Pelo Processo de Redução da Cassiterita a Estanho}

Para o tratamento de Efluente Industrial, neste caso a água residual, seja eficiente consideram-se os fatores como os custos de investimento; os custos operacionais; a quantidade e a qualidade do lodo gerado; a qualidade do efluente tratado; segurança relativa aos vazamentos de produtos químicos utilizados ou dos efluentes; explosões; geração de odor, além da confiabilidade para atendimento a legislação ambiental e possibilidade de reuso dos efluentes tratados (GIORDANO, 2004).

Para a Companhia de Tecnologia de Saneamento Ambiental - (CETSB), o tratamento mais utilizado em indústria que utilizam água no seu processo é a neutralização, precipitação e remoção dos sólidos precipitados. Os efluentes ácidos alcalinos são misturados em caixas ou tanques com agitação mecânica, onde é feito o acerto de $\mathrm{pH}$ pela adição de ácido/base com formação de precipitados. Os agentes químicos mais utilizados para os efluentes ácidos são soda caustica, carbonato de sódio e cal, e para efluentes alcalinos, o acido sulfúrico. A cal tem a desvantagem de ser pouco solúvel, sendo mais complicado o seu manuseio 
Tabela 02 - Resultados analíticos após a adição de reagente Hidróxido de Sódio $(\mathrm{NaOH})$.

\begin{tabular}{|c|c|c|c|}
\hline Parâmetros & $\mathrm{LQ}(\mathrm{mg} / \mathrm{l})$ & $\begin{array}{c}\text { Resultados } \\
\text { analíticos (mg/l) }\end{array}$ & $\begin{array}{c}\text { CONAMA } 357 \text { - Art. } 34 \\
\text { VMP (mg/l) }\end{array}$ \\
\hline Cobre Dissolvido & 0,005 & 0,032 & 1,0 \\
\hline Ferro Dissolvido & 0.5 & 2,8 & 15,0 \\
\hline Manganês Dissolvido & 0,01 & 0,093 & 1,0 \\
\hline Fluoreto & 0,1 & 810 & 10,0 \\
\hline $\mathrm{pH}-\left[\mathrm{H}^{+}\right]$ & $0-14$ & 7,00 & $5-9$ \\
\hline Materiais sedimentáveis & 0,3 & $<0,3$ & 1,0 \\
\hline Óleos e Graxas Minerais & 1 & $<1$ & 20.0 \\
\hline Óleos e Graxas Vegetais e Animais & 1 & $<1$ & 50,0 \\
\hline Materiais flutuantes & ... & Ausentes & Ausentes \\
\hline Arsênio Total & 0,01 & $<0,01$ & 0,5 \\
\hline Bário Total & 0,01 & 0,012 & 5,0 \\
\hline Boro Total & 0.01 & 0,239 & 5,0 \\
\hline Cádmio Total & 0,001 & $<0,001$ & 0,2 \\
\hline Chumbo Total & 0,01 & $<0,01$ & 0,5 \\
\hline Cianeto & 0,1 & $<0,05$ & 1,0 \\
\hline Cianeto Livre & 0,02 & $<0,01$ & 0,2 \\
\hline Cromo Hexavalente & 0.01 & $<0,01$ & 0.1 \\
\hline Cromo Trivalente & 0,01 & 0,06 & 1,0 \\
\hline Cromo & 0,01 & 0,061 & --. \\
\hline Estanho Total & 0.5 & 1.5 & 4.0 \\
\hline Mercúrio Total & 0,00025 & $<0,00006$ & 0.01 \\
\hline Níquel Total & 0,01 & $<0,01$ & 2,0 \\
\hline Nitrogênio Amoniacal & 0,1 & 0,56 & 20,0 \\
\hline Prata Total & 0,005 & $<0,005$ & 0,1 \\
\hline Selênio Total & 0,008 & $<0,008$ & 0,30 \\
\hline Sulfeto & 1,0 & $<1$ & 1,0 \\
\hline Zinco Total & 0,01 & 0,460 & 5,0 \\
\hline Clorofórmio & 0,001 & $<0,001$ & 1,0 \\
\hline Dicloroeteno Total & 0,003 & $<0,003$ & 1,0 \\
\hline Índice de Fenóis & 0,02 & $<0,02$ & 0,5 \\
\hline Tetracloreto de Carbono & 0.001 & $<0,001$ & 1.0 \\
\hline Tricloroeteno & 0,001 & $<0,001$ & 1,0 \\
\hline
\end{tabular}

Fonte: Dados da análise laboratorial

Tabela 03 - Comparativo da primeira análise com a segunda análise após a adição do reagente $\mathrm{NaOH}$.

\begin{tabular}{|c|c|c|c|}
\hline PARÂMETROS & $\begin{array}{c}\text { CONAMA } 357 \text { - Art. } 34 \\
\text { VMP (mg/l) }\end{array}$ & $\begin{array}{c}1^{\text {a }} \text { ANÁLISE } \\
(\mathrm{mg} / \mathrm{l})\end{array}$ & $\begin{array}{l}2^{\text {a }} \text { ANÁLISE } \\
(\mathrm{mg} / \mathrm{l})\end{array}$ \\
\hline Cobre Dissolvido & 1,00000 & 0,09100 & 0,03200 \\
\hline Ferro Dissolvido & 15,00000 & 34,80000 & 2,80000 \\
\hline Manganês Dissolvido & 1,00000 & 0,32200 & 0,09300 \\
\hline Fluoreto & 10,00000 & 710,00000 & 810,00000 \\
\hline $\mathrm{pH}-\left[\mathrm{H}^{+}\right]$ & 5,00000 & 2,74000 & 7,00000 \\
\hline Materiais sedimentáveis & 1,00000 & 0,70000 & 0,30000 \\
\hline Arsênio Total & 0,50000 & 0,01000 & 0,01000 \\
\hline Bário Total & 5,00000 & 0,25000 & 0,01200 \\
\hline Boro Total & 5,00000 & 0,49500 & 0,23900 \\
\hline Cádmio Total & 0.20000 & 0,00100 & 0.00100 \\
\hline Chumbo Total & 0,50000 & 0,01000 & 0,01000 \\
\hline Cianeto & 1,00000 & 0,10000 & 0,05000 \\
\hline Cianeto Livre & 0,20000 & 0,02000 & 0,01000 \\
\hline Cromo & 0.00000 & 0.02200 & 0.06100 \\
\hline Estanho Total & 4,00000 & 6,40000 & 1,50000 \\
\hline Mercúrio Total & 0,01000 & 0,00025 & 0,00006 \\
\hline Níquel Total & 2,00000 & 0,02900 & 0,01000 \\
\hline Nitrogênio Amoniacal & 20,00000 & 0.70000 & 0.56000 \\
\hline Prata Total & 0,10000 & 0.00500 & 0.00500 \\
\hline Selênio Total & 0,30000 & 0,00800 & 0,00800 \\
\hline Sulfeto & 1,00000 & 1,00000 & 1,00000 \\
\hline Zinco Total & 5.00000 & 0,79000 & 0.46000 \\
\hline Clorofórmio & 1.00000 & 0,00100 & 0,00100 \\
\hline Dicloroeteno Total & 1,00000 & 0,00300 & 0,00300 \\
\hline Índice de Fenóis & 0,50000 & 0,15000 & 0,02000 \\
\hline Tetracloreto de Carbono & 1,00000 & 0,00100 & 0,00100 \\
\hline Tricloroeteno & 1.00000 & 0.00100 & 0.00100 \\
\hline
\end{tabular}

Fonte: Dados da análise laboratorial 


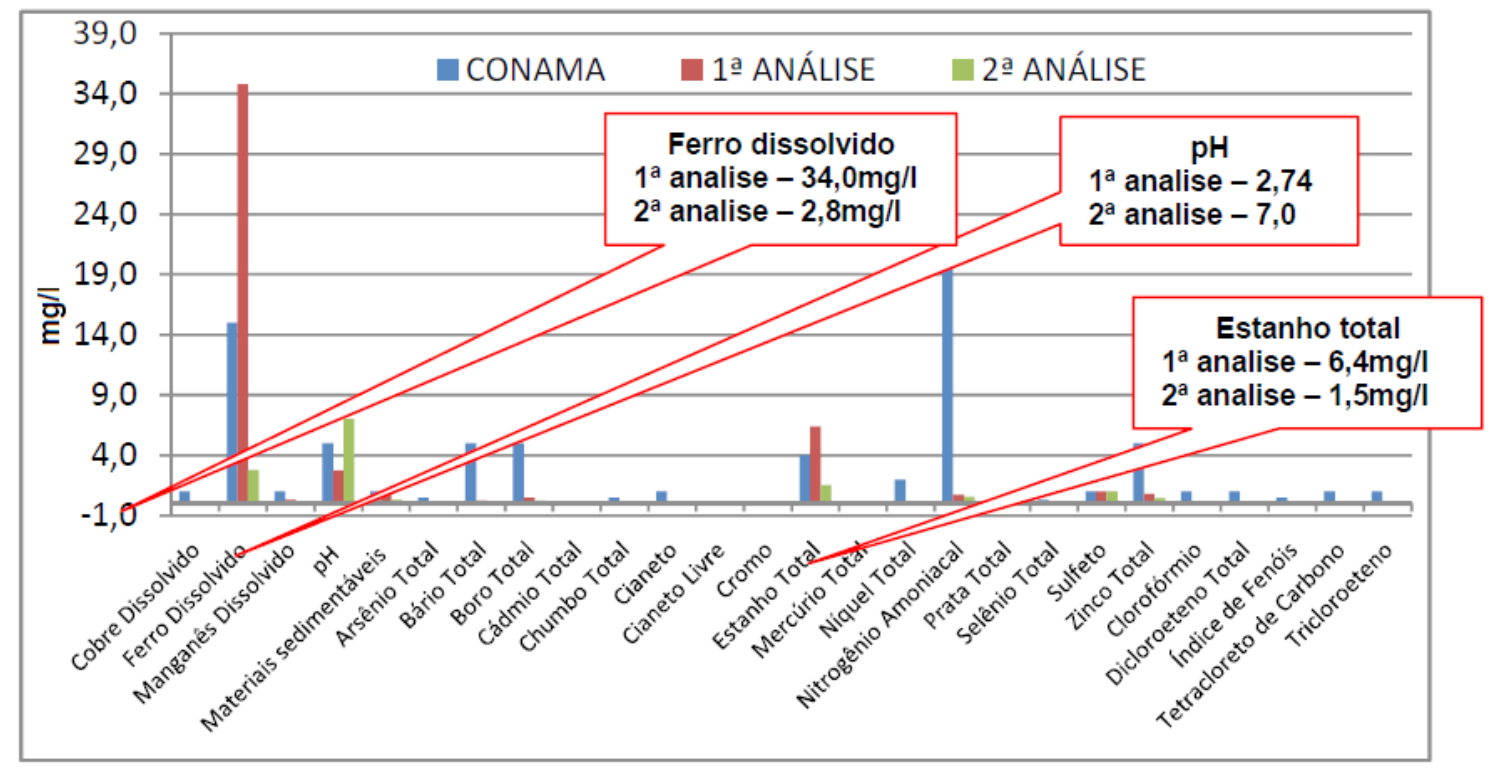

Figura 2. Comparação entre os resultados das amostras e limites da Resolução CONAMA 357/2005.

Fonte: Elaborado pelo autor.

e a dosagem, mas por outro lado é um produto barato, com a produção de um lodo mais denso e fácil de secar. Já o $\mathrm{NaOH}$ tem a vantagem de não necessitar de sistemas sofisticado de dosagem, e a produção do lodo é bem menor (CONAMA, 2005).

Observou-se que a neutralização através de hidróxido de sódio foi eficiente para redução dos níveis de estanho e ferro. Em relação ao $\mathrm{pH}$ houve um aumento imediato, passado de 2,74 para 7,0 , mas a não redução dos índices de fluoreto poderão, no decorrer do tempo,pode fazer com que o $\mathrm{pH}$ retorne ao índices anteriores.

Considerando que a neutralização com hidróxido de sódio não interferiu na concentração de fluoreto, sugere-se, para tanto, a utilização de processos como a de precipitação, de adsorção através de carvão ativado, alumina e resina de troca iônica (SILVA et al., 2006).

A utilização de alumina para a remoção de flúor em grandes proporções teve início na usina de Bartlett, (Usina de desfluoretação, construída em 1952 que empregava alumina ativada como trocador iônico e em 1977 foi fechada) Texas, Estados Unidos, nos anos de 1952 a 1977, mostrando-se eficiente, alcançando índices em torno de 1560 $\mathrm{g}$ de fluoreto por $\mathrm{m}^{3}$ de alumina, e em água com um teor de $8 \mathrm{mg} / \mathrm{L}$. Essa capacidade reduziu-se para $920 \mathrm{~g}$ fluoreto por $\mathrm{m}^{3}$ de alumina quando a água apresentava um teor de $3 \mathrm{mg} / \mathrm{L}$ de fluoreto (MAIER, 1971).

Em estudo realizado em poços da região metropolitana da cidade de São Paulo constatou-se que a utilização de agentes a base de ortofosfatos mostrou-se eficiente na remoção de fluoretos, além de ser de baixo custo inicial e de manutenção (NETTO et al., 2004).

Dependendo da natureza do resíduo a ser tratado são necessários vários processos de tratamento de resíduo líquido, para que o mesmo se enquadre os padrões estabelecidos pela Legislação Ambiental. Geralmente, a primeira etapa o resíduo líquido contendo metais pesados é a através da coagulação química, a qual pode influenciar significativamente nas etapas de tratamento subsequentes (JULIO et al., 2009).

Diante dos resultados obtidos e comprovados através de análises químicas dos contaminantes, sugere-se, para remoção de fluoreto, processos de precipitação e ou adsorção, com a utilização de alumina (oxido de alumínio, formado por alumínio e oxigênio), carvão ativado (carbono tratado para aumentar significativamente suas propriedades de adsorção, eliminando odores, mau gosto e substâncias orgânicas dissolvidas), resina de troca iônica ou agentes a base de ortofosfatos (usado para captar em meio líquido cátions e anions, responsável por teor de sólidos dissolvidos indesejáveis). O processo de adsorção é usado na remoção de compostos orgânicos e metais pesados presentes em águas residuárias ou efluentes industrial, sendo um processo bastante eficiente na sua remoção. Quanto aos demais a neutralização com hidróxido de sódio poderá ser mantida. Para tanto, se faz necessário testes para verificar a eficiência e custo para cada caso. 


\section{CONCLUSÃO}

As amostras foram coletadas e enviadas para o laboratório, em duas etapas, sendo que na primeira etapa apresentou elementos fora dos padrões do CONOMA, a exemplo do $\mathrm{pH} 2,74$ $\mathrm{mg} / \mathrm{L}$ com valor mínimo $\mathrm{pH} 5,0$ e no máximo $\mathrm{pH} 9,0$, o estanho dissolvido $6,4 \mathrm{mg} / \mathrm{L}$, com valor máximo permitido de $4,0 \mathrm{mg} / \mathrm{L}$, ferro total 34,8 $\mathrm{mg} / \mathrm{L}$, com valor máximo permitido $15,0 \mathrm{mg} / \mathrm{L}$ e fluoreto $710 \mathrm{mg} / \mathrm{L}$, valor máximo permitido (10,0 mg/L).

Na segunda etapa, após a neutralização com hidróxido de sódio os resultados analítico foram satisfatório em relação à remoção do ferro, estanho e no tocante a elevação do $\mathrm{pH}$ a níveis aceitáveis. Ao se tratar do parâmetro fluoreto não apresentou resultado satisfatório perante a legislação aplicada (Conama 357/05, art. 34) com resultado de $810 \mathrm{mg} / \mathrm{L}$ enquanto o valor máximo permitido é de $10,0 \mathrm{mg} / \mathrm{L}$.

O fluoreto por estar dissolvido na água residual não precipitou como o esperado. Para tanto, sugere-se a remoção do mesmo através da precipitação e ou adsorção, com a utilização de alumina, carvão ativado, resina de trocas iônicas ou agentes a base de ortofosfatos, conforme discutidos anteriormente. Quanto os demais contaminantes a neutralização com hidróxido de sódio poderá ser mantida, portanto, sugere-se a continuidade da pesquisa com vistas à seleção do método para remoção de fluoreto que seja o mais eficiente e com menor custo, visando o reaproveitamento da água residual na linha de produção.

\section{REFERENCIAS}

MELAMED, Ricardo; PEDRO, Heloisa Helena B., LUZ, Adão Benvindo. Eficiência de minerais industriais na sorção de metais pesados. In: Encontro Nacional De Tratamento De Minérios E Metalurgia Extrativa, Recife, Rio de Janeiro, 2002.

TOREM, Mauricio Leonardo; CUNHA, Fabíola oliveira da cunha; CASQUEIRA, Rui de Góes. Eletrofrotação aplicada a remoção de metais pesados contidos em efluentes liquidos. Revista Tecnologia em Metalurgia e Materiais, São Paulo, v. 1, n. 4, abr. 2005.

PEREIRA, K. C. D. Identificação de eventos de transporte atmosférico por análise de micropartículas no ar e no depósito glacial da Ilha Rei George - Península Antártica. Dissertação (Mestrado em
Biologia) - Instituto de Biologia da Universidade de Estado do Rio de Janeiro, 2002.

APOSTOLLI, P. Apostila do curso Riscos Associados á Exposição de Metais. Escola Nacional de Saúde Pública/ ENSP, Fundação Osvaldo Cruz, FIOCRUZ. Rio de Janeiro, 1992.

CASTANHO, A.; CRUZ, P. A. Perfil analítico das terras raras. Ministério das Minas e Energia. Departamento Nacional de Produção e Mineração, boletim 28. Rio de Janeiro: DNPM, 1973.

MORAES, L. S. D.; JORDÃO, Q. B. Degradação de Recursos Hídricos e seus Efeitos sobre a Saúde Humana. Rev Saúde Pública, v.36, n. 3, p.370-4, 2002.

MARCUS, Gilson. Separação, Tratamento de água, meio ambiente. Ano x, Revista e Portal Meio Filtrante, n.51, jun./ago. 2011.

CONAMA - CONSELHO NACIONAL DO MEIO AMBIENTE. Resolução Conama 357/05 Art. 34. Dispõe sobre a classificação dos corpos de água e diretrizes ambientais para seu enquadramento, bem como estabelece as condições e padrões de lançamento de efluente e dá outras providências. 2005.

GIORDANO, Gandhi. Tratamento e Controle de Efluentes Industriais. Mato Grosso. 2004. Disponível em: <http://www.ufmt.br/esa/Modulo_II_Efluentes_Industriais/Apost_EI_2004_1ABES_Mato_ Grosso_UFMT2.pdf >. Acesso em: 6 jun. 2011.

SILVA, C. A et al. Uso da Moringa Oleifera para Remoção de Fluor em águas, Revista Analytica, n. 21, fev./mar., 2006.

MAIER, F. J., "Water defluoridation of Britton : End of an Era". Public Works, v. 102, n. 6, 1971.

NETTO, João Paulo Godoi Martins et al, . A Ocorrência de Fluoreto na Água de Poços da Região Metropolitana de São Paulo e Novas Tecnologias Para Sua Remoção. In: XIII Congresso Brasileiro De Àguas Subterrâneas, 13º, Cuiabá, MT, 2004.

JULIO, Marcelo. et al. Influência dos Parâmetros de Mistura Rápida, Floculação e Decantação no Tratamento da Água Afluente à ETA de Ponta Grossa/ PR. 2009. 17 f. Monografia, (Engenharia de Alimentos) - Universidade Estadual de Ponta Grossa, Ponta Grossa - PR, 2009. 
ZAN, R.A.; FARIAS, C.C.; BRONDANI, F.M.M.; BARBOSA, N.V.; MENEGUETTI, D.U.O. Ensino Interdisciplinar da Educação Ambiental nas disciplinas de Biologia e Química do Ensino Médio: uma proposta para as escolas públicas do município de Ariquemes, Rondônia, Brasil. Revista Monografias Ambientais (Remoa/UFSM). v. 7, n. 7, p.1630-1645, 2012. 